\title{
Extracorporeal membrane oxygenation: A bridge too far... no more
}

\author{
Michael K. Hsin, MD, and Tim W. K. Au, MD
}

\author{
From the Department of Cardiothoracic Surgery, Queen Mary Hospital, Hong Kong, People's Republic of China. \\ Disclosures: Authors have nothing to disclose with regard to commercial support. \\ Received for publication Aug 27, 2017; accepted for publication Aug 28, 2017; available ahead of print Sept 28, \\ 2017. \\ Address for reprints: Michael K. Hsin, MD, Department of Cardiothoracic Surgery, Queen Mary Hospital, \\ 102 Pok Fu Lam Rd, Hong Kong (E-mail: mkhsin@hotmail.com). \\ J Thorac Cardiovasc Surg 2017;154:e129-30 \\ 0022-5223/ $\$ 36.00$ \\ Copyright $(2017$ by The American Association for Thoracic Surgery \\ http://dx.doi.org/10.1016/j.jtcvs.2017.08.098
}

In this issue, Spratt and colleagues ${ }^{1}$ report a case of acute interstitial pneumonitis causing acute respiratory failure in a young patient who was bridged to transplant (BTT) with venovenous extracorporeal membrane oxygenation (ECMO) and was doing well at 2 years after lung transplant (LTx). This encouraging result should be viewed in the light of the evolving attitude regarding ECMO as BTT over the past 2 decades.

The use of ECMO as BTT was attempted in $1975,{ }^{2}$ but poor outcomes discouraged widespread application. ${ }^{3,4}$ Until 2010, many centers considered patients requiring mechanical ventilation (MV) too sick to undergo LTx, as reflected in the International Society for Heart and Lung Transplantation 2006 guidelines. ${ }^{5}$

During 2010, an analysis of the United Network for Organ Sharing database showed that posttransplant survival at 1 year was $62 \%$ for recipients bridged with $\mathrm{MV}, 50 \%$ for those bridged with ECMO, and 79\% for unsupported patients. ${ }^{6}$ The risks associated with MV were considered acceptable by some, but many centers declined to transplant patients receiving MV. Clinicians were more guarded regarding BTT with ECMO. However, in the United States, the introduction of the Lung Allocation Score in 2005 gave priority to the medical urgency of the patient over duration on the waiting list, which has led to priority for sicker patients and an increase in demand for BTT.

Hayanga and colleagues ${ }^{7}$ analyzed the United Network for Organ Sharing data from 12,458 adults who underwent LTx between 2000 and 2011. The study period was divided into 43 year intervals. The 1-year survival for those bridged with ECMO, compared with patients without BTT, progressively increased with each period: $25.0 \%$ versus $81.0 \%$ (20002002), $47.1 \%$ versus $84.2 \%$ (2006-2008), and 74.4\% versus $85.7 \%$ (2009-2011). A similar rising trend was observed with the number of patients bridged with ECMO. ${ }^{7}$

A systematic review of 14 studies, all published since 2010, concluded that using ECMO as BTT was associated with high perioperative morbidity and mortality, but achieved acceptable 1-year survival, very similar to that alternative to $\mathrm{MV}^{8}$

\section{References}

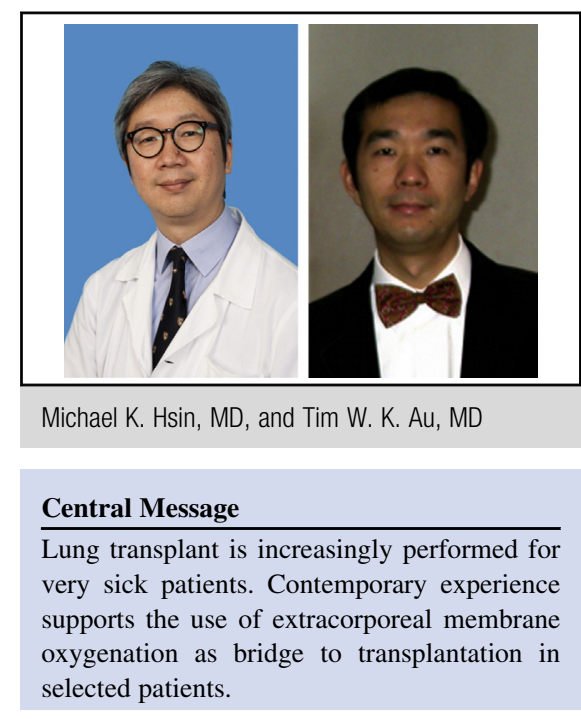

See Article page e125.

of MV patients. However, it was not possible to delineate the efficacy of ECMO as BTT in addition to or as an

A recent retrospective series from Pittsburgh, comprising 826 LTx cases, studied the influence of using MV, with or without ECMO, before LTx on survival after transplantation. ${ }^{9}$ The authors found no difference in overall survival between the MV and MV + ECMO groups. The MV + ECMO group had significantly higher survival conditioned on surviving to 1 year, although these recipients were more likely to require ECMO after transplant.

The factors that contributed to the improved outcomes in the more contemporary series using ECMO as BTT included hollow-fiber polymethylpentine oxygenators, improved levitated centrifugal pumps, heparin-bonded circuits, and better patient/donor selection.

When deciding whether a patient should be bridged for transplant, important factors to consider are age, functional status, other organ dysfunction, and anticipated time on a waiting list. ${ }^{10}$ Moreover, it has been shown that ECMO bridge duration shorter than 14 days resulted in better survival; therefore, these patients should be routinely reassessed regarding their eligibility for transplantation. ${ }^{8}$

1. Spratt JR, Racila E, Shumway SJ. Acute interstitial pneumonitis requiring extracorporeal membrane oxygenation and lung transplantation in an adolescent patient. J Thorac Cardiovasc Surg. 2017;154:e125-7. 
2. Veith FJ. Lung transplantation. Transplant Proc. 1977;9:203-8.

3. Zapol WM, Snider MT, Hill JD, Fallat RJ, Bartlett RH, Edmunds LH, et al. Extracorporeal membrane oxygenation in severe acute respiratory failure. A randomized prospective study. JAMA. 1979;242:2193-6.

4. Diaz-Guzman E, Hoopes CW, Zwischenberger JB. The evolution of extracorporeal life support as a bridge to lung transplantation. ASAIO J. 2013;59:3-10.

5. Orens JB, Estenne M, Arcasoy S, Conte JV, Corris P, Egan JJ, et al. International Guidelines for the Selection of Lung Transplant Candidates: 2006 update-a consensus report From the Pulmonary Scientific Council of the International Society for Heart and Lung Transplantation. J Heart Lung Transplant. 2006;25:745-55.

6. Mason DP, Thuita L, Nowicki ER, Murthy SC, Pettersson GB, Blackstone EH Should lung transplantation be performed for patients on mechanical respiratory support? The US experience. J Thorac Cardiovasc Surg. 2010;139:765-73.
7. Hayanga A, Aboagye J, Esper S, Shigemura N, Bermudez CA, D'Cunha J, et al. Extracorporeal membrane oxygenation as a bridge to lung transplantation in the United States: an evolving strategy in the management of rapidly advancing pulmonary disease. J Thorac Cardiovasc Surg. 2015;149:291-6.

8. Chiumello D, Coppola S, Froio S, Colombo A, Del Sorbo L. Extracorporeal life support as bridge to lung transplantation: a systematic review. Crit Care. 2015; 19:19.

9. Hayanga A, Du A, Joubert K, Tuft M, Baird R, Pilewski J, et al. Mechanical ventilation and extracorporeal membrane oxygenation as a bridging strategy to lung transplantation: significant gains in survival. Am J Transplant. July 11, 2017 [Epub ahead of print].

10. Biscotti M, Sonett J, Bacchetta M. ECMO as bridge to lung transplant. Thorac Surg Clin. 2015;25:17-25. 